\title{
AGE AND SEX VARIABILITY OF INITIAL PARTS OF THE QRS COMPLEX DISPLAYED IN ISOINTEGRAL MAPS OF YOUNG PEOPLE
}

\author{
Katarína Kozliková, Juraj Martinka \\ Comenius University, Faculty of Medicine, Bratislava, Slovak Republic: Institute of Medical Physics and Biophysics
}

\begin{abstract}
Summary: Although body surface electrocardiographic mapping is used also in clinical practice, there are only a few papers concerning the isointegral maps (IIMs) in children. We constructed IIMs of 169 healthy young people during the initial parts of the QRS complex: the first $20 \mathrm{~ms}\left(\mathrm{QRS}_{20}\right), 30 \mathrm{~ms}\left(\mathrm{QRS}_{30}\right), 40 \mathrm{~ms}\left(\mathrm{QRS}_{40}\right)$, and from $20 \mathrm{~ms}$ to $40 \mathrm{~ms}\left(\mathrm{QRS}_{20-40}\right)$. Subjects were divided into 6 groups: 9-10 y (F1, M1), 13-14 y (F2, M2), 18-19 y (F3; M3). We analysed the extreme values of each time integral. We found maxima and peak-to-peak values decreasing with age, while minima tended to increase (became less negative). Most age differences were found in IIM QRS ${ }_{20-40}$ and between peak-to-peak values. Least differences were between minima. Maxima and peak-to-peak values were higher in males than in females. No significant differences were found in any extreme value between groups F1 and M1 except for IIM $\mathrm{QRS}_{20}$ maxima. Significant sex differences increased with age. The only significant difference found in minima was between F2 and M2. Most sex differences were found in IIM QRS ${ }_{20}$. We assume that our findings can be explained (at least in part) by the influence of heart - chest geometry.
\end{abstract}

Key words: Body surface mapping; Isointegral map; QRS complex; Children; Statistical analysis

\section{Introduction}

Physiologic values of electrocardiographic parameters are important to be known before stating the diagnosis. Individual characteristics of isointegral maps (IIMs) are influenced by different factors such as age or sex. They may contribute to relatively high variability among measured parameters of patients or control subjects. Although it is important to know how these factors may affect used IIM characteristics, isointegral mapping of controls in different age and sex groups is very rare $(8,9,10,11)$. Only a very little is known about IIM parameters in children $(1,3,4,5,6,8,9)$. In our study we tried to fill in this gap with amplitude analysis of IIMs of initial parts of the QRS complex in children and young adults.

\section{Patients and Methods}

We recorded and analysed IIMs of 169 young healthy people (90 females and 79 males). They were chosen from over 200 records of young people from which subjects revealing any electrocardiographic abnormality or any technical problem of the record were excluded. Remaining subjects were distributed into six groups after their age and sex: 9-10 years (group F1: 17 girls; group M1: 15 boys), 13-14 years (F2: 25 girls; M2: 23 boys), and 18-19 years
(F3: 48 women; M3: 41 men). None of measured subjects suffered by any cardiovascular disease or had any abnormality found neither on 12-lead standard electrocardiograms or M-mode echocardiograms.

We used the limited 24-lead system after Barr implanted in the mapping system ProCardio $(2,12)$ for the recording of the electric heart field and data processing. During each examination a record of one second duration was registered (a single heartbeat) in supine position. Linear baseline was taken through T-P segments. The onset and offset of the QRS complex was established manually from the root mean square signal (7).

We compared extreme values of IIMs (maximum, minimum, and peak-to-peak value $=$ maximum - minimum $)(7)$. For construction of IIMs we used following integration intervals: the first $20 \mathrm{~ms}$ (IIM QRS ${ }_{20}$ ), the first $30 \mathrm{~ms}$ (IIM $\mathrm{QRS}_{30}$ ), and the first $40 \mathrm{~ms}$ of QRS complex (IIM QRS ${ }_{40}$ ), and the interval from $20 \mathrm{~ms}$ to $40 \mathrm{~ms}$ of QRS complex (IIM $\mathrm{QRS}_{20-40}$ ).

Statistical analysis was performed in following way using the program Statgraphics 3 plus (13). All data were tested for normal distributions using skewness and kurtosis. If they were found normal, variance check was done using Bartlett's test (age differences). If variances were found to be the same, analysis of variance was used with Fisher's least significant differences. If any of previous conditions 

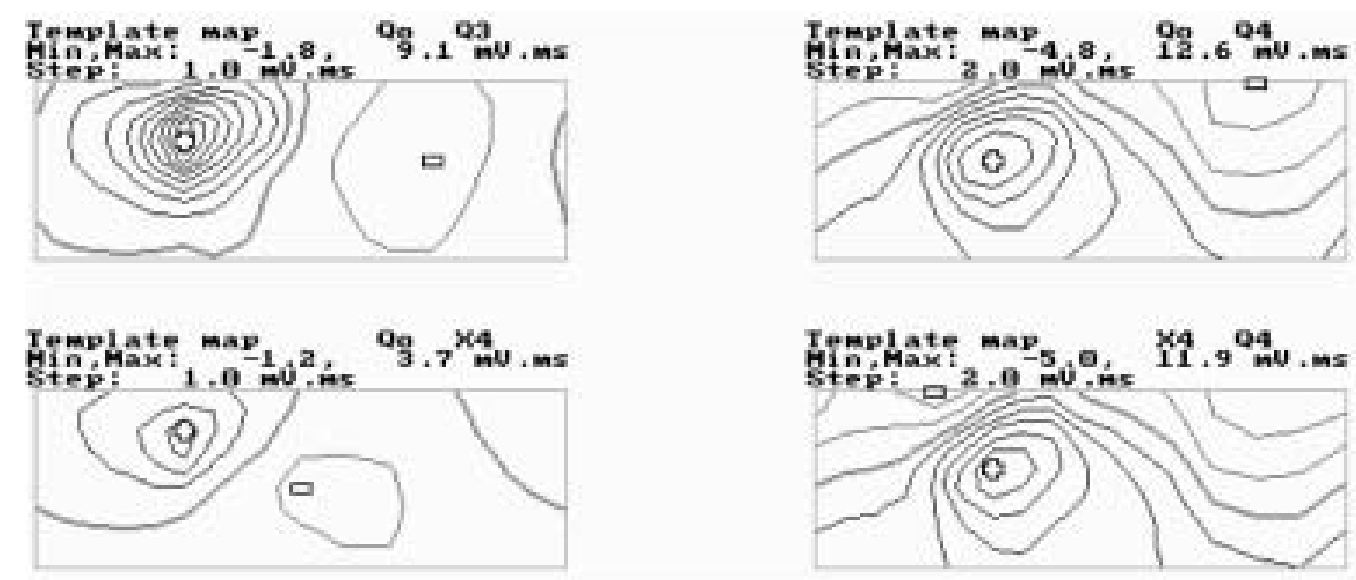

Fig. 1: Mean IIMs of group F3. Each rectangle displays chest surface with the anterior chest on the right and back on the left. Maximal and minimal values are marked by plus and minus signs, respectively, and displayed above each map. Step concerns the difference between two successive isointegral lines. Template (group) maps are marked as QoQ3 (IIM $\mathrm{QRS}_{30}$ ), QoQ4 (IIM QRS 40 ), QoX4 (IIM QRS 20 ), and X4Q4 (IIM QRS $\left.20-40\right)$.
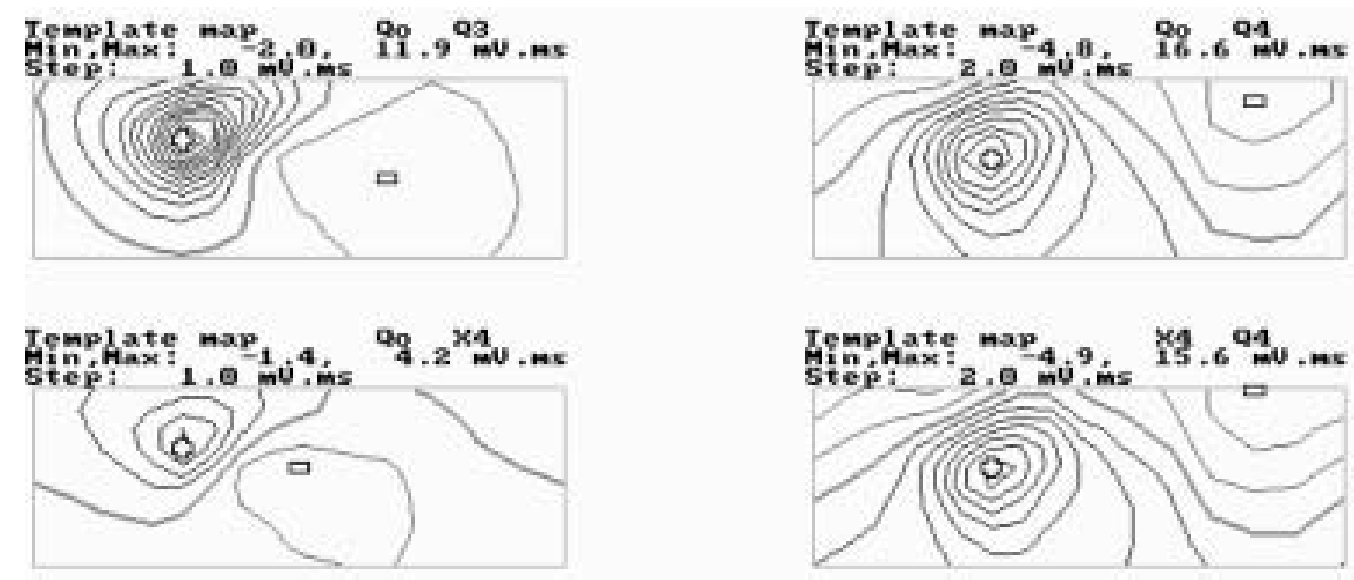

Fig. 2: Mean IIMs of group M3. Next description as in Figure 1.

Tab. 1: Values of maxima in isointegral maps in all studied groups and differences between sexes of the same age.

\begin{tabular}{|c|c|c|c|c|c|c|}
\hline $\begin{array}{l}\text { Group } \\
\text { IIM }\end{array}$ & $\begin{array}{c}\mathbf{F 1} \\
(\mathrm{n}=17)\end{array}$ & $\begin{array}{c}\mathbf{F 2} \\
(\mathrm{n}=25)\end{array}$ & $\begin{array}{c}\mathbf{F 3} \\
(\mathrm{n}=48)\end{array}$ & $\begin{array}{c}\text { M1 } \\
(n=15)\end{array}$ & $\begin{array}{c}\mathbf{M} 2 \\
(n=23)\end{array}$ & $\begin{array}{c}\text { M3 } \\
(n=41)\end{array}$ \\
\hline $\mathbf{Q R S}_{20}$ & $\begin{array}{c}5.1 \pm 1.8 \\
(5.4) \\
\langle 2.2 ; 8.6>\end{array}$ & $\begin{array}{c}4.1 \pm 1.4 \\
(3.7) \\
<1.7 ; 6.9>\end{array}$ & $\begin{array}{c}3.8 \pm 1.3^{\#} \\
(3.8) \\
<1.3 ; 9.3>\end{array}$ & $\begin{array}{c}6.7 \pm 2.5^{*} \\
(6.5) \\
<3.0 ; 12.0>\end{array}$ & $\begin{array}{l}5.0 \pm 1.5^{*} \\
(4.9)^{*} \\
\langle 2.1 ; 7.6\rangle\end{array}$ & $\begin{array}{c}4.6 \pm 1.4 \\
(4.4)^{\&} \\
<2.6 ; 8.5>\end{array}$ \\
\hline $\mathbf{Q R S}_{30}$ & $\begin{array}{c}12.9 \pm 4.0 \\
(12.0) \\
<5.7 ; 21.7>\end{array}$ & $\begin{array}{c}11.2 \pm 4.0 \\
(10.4) \\
<5.7 ; 19.3>\end{array}$ & $\begin{array}{c}9.9 \pm 3.0^{\#} \\
(9.8) \\
<3.7 ; 20.2>\end{array}$ & $\begin{array}{c}16.7 \pm 6.7 \\
(15.7) \\
<6.8 ; 29.7>\end{array}$ & $\begin{array}{c}14.0 \pm 4.1 * \\
(13.6)^{*} \\
\langle 6.7 ; 19.6>\end{array}$ & $\begin{array}{c}12.8 \pm 4.1 \\
(12.9) \& \& \\
\langle 6.6 ; 21.8>\end{array}$ \\
\hline $\mathbf{Q R S}_{\mathbf{4 0}}$ & $\begin{array}{c}23.4 \pm 8.0 \\
(21.6) \\
<11.7 ; 42.2>\end{array}$ & $\begin{array}{c}18.8 \pm 6.9^{\#} \\
(16.8) \\
<7.0 ; 37.6>\end{array}$ & $\begin{array}{c}14.6 \pm 5.2^{\#} \\
(14.1) \\
\langle 6.3 ; 32.7>\end{array}$ & $\begin{array}{c}23.3 \pm 7.0 \\
(23.0) \\
\langle 12.6 ; 36.0>\end{array}$ & $\begin{array}{c}23.1 \pm 6.7 \\
(22.5)^{*} \\
<14.5 ; 38.3>\end{array}$ & $\begin{array}{l}20.7 \pm 6.8 \\
(21.2) \& \& \& \\
<9.2 ; 43.1>\end{array}$ \\
\hline $\mathrm{QRS}_{20-40}$ & $\begin{array}{c}24.4 \pm 7.1 \\
(22.9) \\
<12.6 ; 39.8>\end{array}$ & $\begin{array}{c}17.9 \pm 6.2^{\#} \\
(15.9) \\
<7.4 ; 35.4>\end{array}$ & $\begin{array}{c}13.5 \pm 4.8^{\#} \\
(12.1) \\
<6.0 ; 30.2>\end{array}$ & $\begin{array}{c}23.0 \pm 5.7 \\
(21.7) \\
<14.8 ; 30.8>\end{array}$ & $\begin{array}{c}22.6 \pm 6.5^{\#} \\
(21.1)^{* *} \\
<14.6 ; 38.5>\end{array}$ & $\begin{array}{l}18.9 \pm 6.5^{\#} \\
(19.5) \& \& \& \\
<7.1 ; 42.5>\end{array}$ \\
\hline
\end{tabular}

${ }^{\#}$ Values were not distributed normally. Statistical significance: ${ }^{*} \mathrm{p}<0.05 ;{ }^{\&} \mathrm{p}<0.01 ;{ }^{* *} \mathrm{p}<0.005 ;{ }^{\& \&} \mathrm{p}<0.001 ;{ }^{\& \& \&} \mathrm{p}<0.0001$. 
was not fulfilled, Kruskal-Wallis test and Mann-Whitney test for medians were used. Sex differences were compared between corresponding age groups in pairs. For normal data Student's t-test was used considering equal or nonequal variances after Fisher's test. Else Mann-Whitney test for medians was used. Statistically significant differences were assumed for $\mathrm{p}<0.05$ or less.

\section{Results}

Mean IIMs of each group revealed smooth dipolar distributions with one maximum and one minimum. The only exception was in the IIM QRS ${ }_{40}$ where an indication of second minimum was found at the right upper back in women (group F3, Figure 1) and in the right clavicular area in men (group M3, Figure 2).

Group extreme values of isointegral maps are given in Tables 1-3 with statistically significant differences found between corresponding sex groups. Values are given in form of mean \pm standard deviation, median in parentheses, range is given below them in form of closed interval. Statistically significant differences concerning the age are given in Tables 4-6. If the comparison is not given, it was not significant.

We found mean maxima and mean peak-to-peak values decreasing with age in all evaluated groups of both sexes (Tables 1 and 3). This trend was valid also for their medians. Minima behaved in a different way (Table 2). In most cases there were the lowest (deep) minima in the youngest children except for IIM QRS ${ }_{40}$ and IIM QRS ${ }_{20-40}$ in group M2. The highest (shallow) minima tended to be in the oldest groups except for IIM QRS ${ }_{30}$ in males where it was found in group M2. Most age differences were found in IIM $\mathrm{QRS}_{20-40}$, which displayed the activation comprising the middle of the QRS complex, and between peak-to-peak values. Least differences were between minima. As more than one third of data sets were not distributed normally, we have taken medians to perform these comparisons.

Tab. 2: Values of minimum in isointegral maps in all studied groups and differences between sexes of the same age.

\begin{tabular}{|l|c|c|c|c|c|c|}
\hline $\begin{array}{l}\text { Group } \\
\text { IIM }\end{array}$ & $\begin{array}{c}\text { F1 } \\
(\mathrm{n}=17)\end{array}$ & $\begin{array}{c}\text { F2 } \\
(\mathrm{n}=25)\end{array}$ & $\begin{array}{c}\text { F3 } \\
(\mathrm{n}=48)\end{array}$ & $\begin{array}{c}\text { M1 } \\
(\mathrm{n}=15)\end{array}$ & $\begin{array}{c}\text { M2 } \\
(\mathrm{n}=23)\end{array}$ & $\begin{array}{c}\text { M3 } \\
(\mathrm{n}=41)\end{array}$ \\
\hline $\mathbf{Q R S}_{\mathbf{2 0}}$ & $-3.6 \pm 4.6^{\#}$ & $-1.6 \pm 0.6$ & $-1.6 \pm 0.4$ & $-2.8 \pm 1.1$ & $-2.2 \pm 0.6^{* *}$ & $-1.8^{* *} \pm 0.6^{\#}$ \\
& $(-2.4)$ & $(-1.5)$ & $(-1.6)$ & $(-2.5)$ & $(-2.2)^{* *}$ & $(-1.8)$ \\
& $<-21.0 ;-1.0>$ & $<-3.0 ;-0.8>$ & $<-2.5 ;-0.9>$ & $<-5.3 ;-1.4>$ & $<-3.5 ;-0.8>$ & $<-3.7 ;-0.8>$ \\
\hline $\mathbf{Q R S}_{\mathbf{3 0}}$ & $-2.7 \pm 0.6$ & $-2.6 \pm 1.1^{\#}$ & $-2.7 \pm 0.8$ & $3.4 \pm 1.2$ & $-2.9 \pm 1.0$ & $-3.0 \pm 1.2^{\#}$ \\
& $(-2.6)$ & $(-2.3)$ & $(-2.7)$ & $(-3.1)$ & $(-2.8)$ & $(-2.7)$ \\
& $<-4.0 ;-1.8>$ & $<-5.4 ;-0.7>$ & $<-4.4 ;-0.9>$ & $<-5.7 ;-1.3>$ & $<-4.8 ;-0.6>$ & $<-8.0 ;-1.3>$ \\
\hline QRS $_{\mathbf{4 0}}$ & $-6.6 \pm 3.0^{\#}$ & $-6.4 \pm 2.4$ & $-5.3 \pm 2.5^{\#}$ & $-6.3 \pm 2.3$ & $-6.9 \pm 3.0^{\#}$ & $-5.4 \pm 2.2^{\#}$ \\
& $(-6.3)$ & $(-5.6)$ & $(-4.6)$ & $(-6.0)$ & $(-6.1)$ & $(-4.9)$ \\
& $<-14.7 ;-2.3>$ & $<-12.9 ;-2.4>$ & $<-13.1 ;-1.6>$ & $<-12.2 ;-2.9>$ & $<-17.4 ;-3.3>$ & $<-12.5 ;-2.5>$ \\
\hline QRS $_{\mathbf{2 0 - 4 0}}$ & $-8.0 \pm 3.7^{\#}$ & $-7.6 \pm 2.5$ & $-5.9 \pm 2.8^{\#}$ & $-7.6 \pm 3.0^{\#}$ & $-7.7 \pm 3.4$ & $-6.0 \pm 3.3^{\#}$ \\
& $(-7.1)$ & $(-6.6)$ & $(-5.0)$ & $(-6.9)$ & $(-6.4)$ & $(-5.2)$ \\
& $<-18.3 ;-3.0>$ & $<-12.9 ;-4.9>$ & $<-15.1 ;-2.3>$ & $<-16.6 ;-4.0>$ & $<-18.0 ;-3.3>$ & $<-18.6 ;-2.1>$ \\
\hline
\end{tabular}

\# Values were not distributed normally. Statistical significance: ${ }^{* *} \mathrm{p}<0.005$.

Tab. 3: Values of peak-to-peak in isointegral maps in all studied groups and differences between sexes of the same age.

\begin{tabular}{|c|c|c|c|c|c|c|}
\hline $\begin{array}{l}\text { Group } \\
\text { IIM }\end{array}$ & $\begin{array}{c}\mathbf{F 1} \\
(\mathrm{n}=17)\end{array}$ & $\begin{array}{c}\mathbf{F 2} \\
(\mathrm{n}=25)\end{array}$ & $\begin{array}{c}\mathbf{F 3} \\
(\mathrm{n}=48)\end{array}$ & $\begin{array}{c}\text { M1 } \\
(n=15)\end{array}$ & $\begin{array}{c}\text { M2 } \\
(n=23)\end{array}$ & $\begin{array}{c}\text { M3 } \\
(n=41)\end{array}$ \\
\hline $\mathbf{Q R S}_{20}$ & $\begin{array}{c}8.7 \pm 4.9^{\#} \\
(7.3) \\
\langle 5.0 ; 26.0>\end{array}$ & $\begin{array}{c}5.7 \pm 1.5 \\
(5.7) \\
<3.5 ; 8.8>\end{array}$ & $\begin{array}{c}5.4 \pm 1.4^{\#} \\
(5.5) \\
<2.2 ; 10.7>\end{array}$ & $\begin{array}{c}9.5 \pm 2.6 \\
(9.5) \\
<5.3 ; 15.3>\end{array}$ & $\begin{array}{l}7.2 \pm 1.8^{* *} \\
\quad(7.3)^{\&} \\
<3.6 ; 9.8>\end{array}$ & $\begin{aligned} & 6.4 \pm 1.7 \\
& (6.2))^{* * *} \\
< & 3.6 ; 10.4>\end{aligned}$ \\
\hline $\mathbf{Q R S}_{30}$ & $\begin{array}{c}15.6 \pm 4.2 \\
(14.4) \\
\langle 8.2 ; 25.5>\end{array}$ & $\begin{array}{c}13.7 \pm 4.7 \\
(12.7) \\
<7.2 ; 23.1>\end{array}$ & $\begin{array}{c}12.6 \pm 3.5^{\#} \\
(12.2) \\
\langle 4.6 ; 24.5\rangle\end{array}$ & $\begin{array}{c}20.1 \pm 7.4 \\
(18.5) \\
\langle 8.1 ; 35.4>\end{array}$ & $\begin{array}{c}16.9 \pm 4.6^{*} \\
(16.3)^{*} \\
\langle 8.9 ; 22.6>\end{array}$ & $\begin{array}{c}15.8 \pm 4.8 \\
(15.8)^{* *} \\
<8.5 ; 26.2>\end{array}$ \\
\hline $\mathbf{Q R S}_{\mathbf{4 0}}$ & $\begin{array}{c}29.9 \pm 9.9 \\
(26.5) \\
\langle 14.0 ; 53.6>\end{array}$ & $\begin{array}{c}25.3 \pm 8.8^{\#} \\
(23.2) \\
<9.4 ; 47.8>\end{array}$ & $\begin{array}{c}19.9 \pm 7.1^{\#} \\
(18.4) \\
<7.9 ; 43.8>\end{array}$ & $\begin{array}{c}29.6 \pm 8.3 \\
(29.6) \\
\langle 16.7 ; 43.7>\end{array}$ & $\begin{array}{c}30.0 \pm 7.8 \\
(28.0)^{*} \\
\langle 19.5 ; 47.1>\end{array}$ & $\begin{array}{c}26.1 \pm 8.4 \\
(27.6))^{* * *} \\
\langle 12.0 ; 53.2>\end{array}$ \\
\hline $\mathrm{QRS}_{20-40}$ & $\begin{array}{c}32.4 \pm 9.4 \\
(30.0) \\
<15.6 ; 52.2>\end{array}$ & $\begin{array}{c}25.4 \pm 7.9^{\#} \\
(22.1) \\
<14.0 ; 46.2>\end{array}$ & $\begin{array}{c}19.4 \pm 7.1^{\#} \\
(17.7) \\
\langle 8.5 ; 43.0>\end{array}$ & $\begin{array}{c}30.6 \pm 7.2 \\
(30.5) \\
<18.8 ; 39.9>\end{array}$ & $\begin{array}{c}30.3 \pm 8.3^{\#} \\
(28.3)^{*} \\
\langle 19.9 ; 51.9>\end{array}$ & $\begin{array}{c}24.9 \pm 9.1^{\#} \\
(23.6)^{\& \&} \\
<9.2 ; 56.6>\end{array}$ \\
\hline
\end{tabular}

${ }^{\#}$ Values were not distributed normally. Statistical significance: ${ }^{*} \mathrm{p}<0.05 ;{ }^{* *} \mathrm{p}<0.005 ;{ }^{\& \&} \mathrm{p}<0.001 ;{ }^{* * *} \mathrm{p}<0.0005$. 
Tab. 4: Significant age differences between medians of groups for maxima.

\begin{tabular}{|l|c|c|c|c|c|}
\hline IIM & F1-F2 & F2-F3 & F1-F3 & M1-M2 & M1-M3 \\
\hline QRS $_{\mathbf{2 0}}$ & NS & NS & $\mathrm{p}<0.01$ & $\mathrm{p}<0.05$ & $\mathrm{p}<0.005$ \\
\hline $\mathbf{Q R S}_{\mathbf{3 0}}$ & $\mathrm{NS}$ & $\mathrm{NS}$ & $\mathrm{p}<0.01$ & $\mathrm{NS}$ & $\mathrm{NS}$ \\
\hline $\mathbf{Q R S}_{\mathbf{4 0}}$ & $\mathrm{p}<0.05$ & $\mathrm{p}<0.01$ & $\mathrm{p}<0.0001$ & $\mathrm{NS}$ & $\mathrm{NS}$ \\
\hline $\mathbf{Q R S}_{\mathbf{2 0 - 4 0}}$ & $\mathrm{p}<0.005$ & $\mathrm{p}<0.005$ & $\mathrm{p}<0.0001$ & $\mathrm{NS}$ & $\mathrm{p}<0.05$ \\
\hline
\end{tabular}

NS: not significant

Tab. 5: Significant age differences between medians of groups for minima.

\begin{tabular}{|l|c|c|c|c|c|}
\hline IIM & F1-F2 & F2-F3 & F1-F3 & M2-M3 & M1-M3 \\
\hline $\mathbf{Q R S}_{\mathbf{2 0}}$ & $\mathrm{p}<0.005$ & $\mathrm{NS}$ & $\mathrm{p}<0.0001$ & $\mathrm{NS}$ & $\mathrm{p}<0.001$ \\
\hline $\mathbf{Q R S}_{\mathbf{4 0}}$ & $\mathrm{NS}$ & $\mathrm{p}<0.05$ & $\mathrm{NS}$ & $\mathrm{p}<0.05$ & $\mathrm{NS}$ \\
\hline $\mathbf{Q R S}_{\mathbf{2 0} \mathbf{4 0}}$ & $\mathrm{NS}$ & $\mathrm{p}<0.005$ & $\mathrm{p}<0.05$ & $\mathrm{p}<0.05$ & $\mathrm{p}<0.05$ \\
\hline
\end{tabular}

NS: not significant

Tab. 6: Significant age differences between medians of groups for peak-to-peak values.

\begin{tabular}{|l|c|c|c|c|c|c|}
\hline IIM & F1-F2 & F2-F3 & F1-F3 & M1-M2 & M2-M3 & M1-M3 \\
\hline QRS $_{\mathbf{2 0}}$ & $\mathrm{p}<0.01$ & $\mathrm{NS}$ & $\mathrm{p}<0.001$ & $\mathrm{p}<0.01$ & $\mathrm{NS}$ & $\mathrm{p}<0.0005$ \\
\hline $\mathbf{Q R S}_{\mathbf{3 0}}$ & $\mathrm{NS}$ & $\mathrm{NS}$ & $\mathrm{p}<0.01$ & $\mathrm{NS}$ & $\mathrm{NS}$ & $\mathrm{NS}$ \\
\hline $\mathbf{Q R S}_{\mathbf{4 0}}$ & $\mathrm{NS}$ & $\mathrm{p}<0.005$ & $\mathrm{p}<0.0005$ & $\mathrm{NS}$ & $\mathrm{NS}$ & $\mathrm{NS}$ \\
\hline $\mathbf{Q R S}_{\mathbf{2 0 - 4 0}}$ & $\mathrm{p}<0.01$ & $\mathrm{p}<0.0005$ & $\mathrm{p}<0.0001$ & $\mathrm{NS}$ & $\mathrm{p}<0.05$ & $\mathrm{p}<0.05$ \\
\hline
\end{tabular}

NS: not significant

Mean maxima and mean peak-to-peak values were higher in males than in corresponding females except for groups F1 and M1 in IIM QRS ${ }_{40}$ and IIM QRS ${ }_{20-40}$ (Tables 1 and $3)$. This was also valid for medians. No significant differences were found in any extreme value when comparing the youngest girls and boys except for maxima in IIM QRS ${ }_{20}$. The number of significant sex differences increased with increasing age. The only significant difference found in sex minima comparison was between groups F2 and M2 (Table 2). Most sex differences were found at the very beginning of the QRS complex (IIM QRS ${ }_{20}$ ).

\section{Discussion and Conclusions}

We did not found published results of IIMs during the initial parts of QRS complex in children. Similar sex differences were found in two 2 published papers. In the first one, Q-zone maps (from the beginning of the QRS complex to its middle, comparable with our IIM $\mathrm{QRS}_{40}$ ) were analysed in adults (20-46 years old) (10). Forty male subjects had significantly higher maxima than 15 females. Differences between minima were not significant. Published maps were recorded with 117 chest leads. In the second paper, QR maps (comparable with our IIM $\mathrm{QRS}_{40}$ ) were analysed in 18 men and 25 women (18-19 years old) (11). Higher extreme values were found in men.

Age differences were analysed in 2 papers. In both, significantly higher values of maxima in younger children (9-10 years) and deeper minima in older children (13-14 years) were found in IIMs during the whole QRS complex and corresponded with our findings $(8,9)$. These maps were recorded in sitting position using 80 chest electrodes.

When looking at these findings, there still remains the question why we found decreasing values with increasing age in young people. One possible answer is the influence of heart geometry, as well as the geometry heart - chest. Or are the changes during puberty responsible for the differences?

\section{References}

1. Asano Y, Izumida N, Kiyohara K et al. Diagnosis of right ventricular overload by body surface QRST isointegral maps in children with postoperative right bundle branch block. J Electrocardiol 1995;28(3):209-21.

2. Barr RC, Spach MS, Herman-Giddens GS. Selection of the number and positions of measuring locations for electrocardiography. IEEE Trans Biomed Eng 1971; 18(2):125-38

3. Izumida $\mathrm{N}$, Asano $\mathrm{Y}$, Kiyohara $\mathrm{K}$ et al. QRST isointegral map reflects the sudden reduction of right ventricular pressure after balloon pulmonary valvuloplasty. J Electrocardiol 1995;28(3):223-9

4. Izumida N, Asano Y, Kiyohara K et al. Precordial leads QRST time integrals for evaluation of right ventricular overload in children with congenital heart diseases. J Electrocardiol 1997;30(3):257-64

5. Izumida $\mathrm{N}$, Asano $\mathrm{Y}$, Wakimoto $\mathrm{H}$ et al. Analysis of $\mathrm{T}$ wave changes by activation recovery interval in patients with atrial septal defect. Int J Cardiol 2000; $74(2-3): 115-24$

6. Izumida N, Kiyohara K, Asano $\mathrm{Y}$ et al. The body surface QRST isointegral maps in infants with right ventricular overload. Jpn Circulat J 1993;57(2): $123-30$

7. Kozlíková K. Body surface integral maps, their characteristics and methods of quantitative analysis. (in Slovak) Bratisl Med J 1990;91(11):815-23.

8. Kozlíková $\mathrm{K}$, Turzová $\mathrm{M}$, Tyšler $\mathrm{M}$ et al. Body surface integral mapping of ventricular activation in boys during puberty. (in Slovak) Bratisl Med J 1988; 89(9):694-705. 
9. Kozlíková K, Maco M, Sabolová K, Popperová E. Absolute extrema of body surface integral maps in normal children. In: Antalóczy Z, Préda I, eds. Advances in Electrocardiology. Amsterdam: Excerpta Medica, 1990:161-4.

10. Montague JM, Smith ER, Cameron DA et al. Isointegral analysis of body surface maps: Surface distribution and temporal variability in normal subjects. Circulation 1981;63(5):1166-72.

11. Popperová E, Sabolová K, Maco M, Kozlíková K, Tyšler M, Turzová M Isointegral analysis of ventricular activation in young people. In: Janoušek V, Špála M, eds. Current trends in pathophysiology. (in Slovak) Praha: Univerzita Karlova, 1989:325-6.

12. Rosík V, Tyšler M, Turzová M. Portable Device for ECG Mapping. In: Frollo I, Plačková A, eds. Measurement'97. Proceedings, International Conference of Measurement. Bratislava: SAS, 1997:367-70.

13. Statgraphics ${ }^{\circledR}$ PLUS, version 3 for Windows. User manual. Rockville: Manugistics, Inc., 1997:738pp.

Doc. RNDr. Katarína Kozlíková, Ph.D.,

Comenius University, Faculty of Medicine,

Institute of Medical Physics and Biophysics,

Sasinkova 2, SK 81372 Bratislava,

Slovak Republic.

e-mail: katarina.kozlikova@fmed.uniba.sk 